\title{
Monetary value of self-reported diets and associations with sociodemographic characteristics and dietary intake among Japanese adults: analysis of nationally representative surveys
}

\author{
Hitomi Okubo ${ }^{1, *}$, Kentaro Murakami ${ }^{2}$ and Satoshi Sasaki ${ }^{3}$ \\ 'Department of Health Promotion, National Institute of Public Health, 2-3-6 Minami, Wako-shi, Saitama 351-0197, \\ Japan: ${ }^{2}$ Department of Nutrition, School of Human Cultures, University of Shiga Prefecture, Shiga, Japan: \\ ${ }^{3}$ Department of Social and Preventive Epidemiology, School of Public Health, The University of Tokyo, Tokyo, Japan
}

Submitted 21 January 2016: Final revision received 29 March 2016: Accepted 24 May 2016: First published online 30 June 2016

\begin{abstract}
Objective: To examine the relationships of monetary value of diets with sociodemographic and lifestyle characteristics and dietary intake among Japanese adults.

Design: Cross-sectional study based on two nationally representative surveys: the Comprehensive Survey of Living Conditions and the National Health and Nutrition Survey, 2013. Dietary intake was assessed by a $1 \mathrm{~d}$ semi-weighed household dietary record with information on individual proportion of intakes. Diet cost was estimated by linking dietary data with retail food prices. A wide variety of sociodemographic and lifestyle variables were obtained from the two surveys.

Setting: A random sample of nationally representative households in Japan.

Subjects: Japanese adults aged 20 years or older ( $n$ 4658).

Results: Lower energy-adjusted diet cost (Japanese yen/4184kJ) was significantly associated with being younger, having a lower education, less equivalent monthly household expenditure, large household size, less physical activity and living in rented houses. Lower diet cost was associated with a lower intake of pulses, vegetables, fruits, fish, meat and dairy products, and a higher intake of grain, eggs, and fats and oils. At the nutrient level, lower diet cost was associated with a lower intake of protein, alcohol, dietary fibre, cholesterol and all vitamins and minerals examined, and a higher intake of carbohydrate. Diet cost was inversely associated with dietary energy density.

Conclusion: These data suggest that certain low socio-economic subgroups in Japan consume diets of lower monetary value, resulting in a lower quality of food and nutrient intake pattern except for lower sodium, cholesterol and alcohol consumption.
\end{abstract}

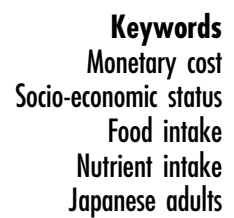

Keywords conomic status Japanese adults
Food price is now considered to be a major determinant influencing food choice ${ }^{(1-3)}$. It is well established in the literature that the more nutrient-rich foods, such as fruits, vegetables and fish, are more expensive per unit of energy than are foods of lower nutritional values such as grain, fats and oils, added sugars and sweets ${ }^{(4-6)}$. The higher cost of some recommended healthy foods may thus restrict their use by people with limited resources ${ }^{(7,8)}$. In fact, lower-quality foods with low cost tend to be selected by groups of lower socio-economic status, who are also more likely to be obese ${ }^{(9-11)}$. Understanding the effect of food prices and diet cost on overall diet quality and identifying vulnerable groups who are more sensitive to food price could bring about new insights related to strategies to prevent socio-economic disparities in health ${ }^{(11-13)}$.
The influence of variation in diet cost on overall diet quality is beginning to receive considerable attention ${ }^{(14-23)}$. There is growing awareness that higher monetary value of diets is linked to better diet in Western countries ${ }^{(14-21)}$, but little is known about this relationship in Asian countries, including Japan ${ }^{(22,23)}$. In a study of young Japanese women, higher monetary diet cost was not necessarily associated with a healthier food and nutrient intake pattern ${ }^{(22,23)}$, which is somewhat in conflict with findings from Western studies ${ }^{(4,14-17,19-21)}$. These inconsistent findings might be partly explained by the differences in food culture between Asian and Western countries. It is necessary to accumulate studies of this kind from various regions with different social and cultural backgrounds in order to obtain reliable scientific evidence on the relationship between diet cost and diet 
quality. It should also be noted that the previous studies conducted in Japan were limited to homogeneous populations of young women, such as female dietetics students ${ }^{(22)}$ and pregnant women ${ }^{(23)}$. Given that food and nutrient intake patterns may vary according to subject characteristics such as sex, age and socio-economic status ${ }^{(24-26)}$, further studies are needed to examine the relationships of monetary diet cost with dietary intake in other Japanese populations.

The objective of the present cross-sectional study was to examine the associations of the monetary value of self-reported diets with sociodemographic and lifestyle characteristics and dietary intake using representative data of Japanese adults.

\section{Subjects and methods}

\section{Study population and procedure}

The present cross-sectional study was based on data from two nationally representative surveys conducted by the Ministry of Health, Labour and Welfare: the 2013 Comprehensive Survey of Living Conditions (CSLC) ${ }^{(27)}$ and the 2013 National Health and Nutrition Survey (NHNS) ${ }^{(28)}$. Data from the two surveys were used with permission from the Japanese Ministry of Health, Labour and Welfare. Detailed descriptions of the CSLC and the NHNS have been published elsewhere ${ }^{(27-29)}$. Briefly, the CSLC has been collecting comprehensive information on the living conditions of people living in Japan such as sociodemographics, health, medical care, welfare and income since 1986 and a large-scale survey has been conducted every three years with a small-scale survey in each interim year $^{(27)}$. The 2013 survey covered 295367 households nationwide that were randomly selected from 5530 census tracts from the National Census $2010^{(30)}$. Five kinds of self-administered questionnaires were distributed to respondents in advance of each survey date (on 6 June for household/health/long-term care questionnaires and on 11 July for income/savings questionnaires) and later collected by trained investigators during home visits. For the present study, we used the data from the household questionnaire to obtain household demographics, education, occupation, marital status, household expenditure in May and housing. Information on income and savings was not available to link to the NHNS because the subjects of the income and the savings questionnaires were different from those of the NHNS. Of the 235012 households that answered the household questionnaire (response rate $=$ $79 \cdot 6 \%)^{(27)}$, data from 234383 households and 603211 household members were provided by the Ministry of Health, Labour and Welfare after excluding unclear answers.

The NHNS, which has been running since 1945, is an annual nationwide survey on the basis of the Health Promotion Law (Law No. 103, enacted in 2002) to assess the health status, food and nutrient intakes and lifestyles of people living in Japan ${ }^{(28,29)}$. The 2013 NHNS comprises: (i) a physical examination (for those aged 1 year or older); (ii) a blood test (aged 20 years or older); (iii) a dietary survey (aged 1 year or older); (iv) pedometer measurement (aged 20 years or older); and (v) a lifestyle questionnaire (aged 20 years or older). Participants are household members aged 1 year or older (as of 1 November 2013) of households living in the 300 unit blocks (approximately 5700 households and 15000 household members) that were randomly selected from the 11000 unit blocks (5530 census tracts) of the CSLC in 2013. Of the 5204 eligible households in the 300 unit blocks, dietary data were obtained from a total of 3493 households $(\text { response rate }=67 \cdot 1 \%)^{(28,29)}$. The exact number of participants approached was not officially published. For the present analysis, we restricted to the 5607 adults aged 20 years or older who completed all three surveys of physical examination, dietary survey and lifestyle questionnaire (Fig. 1). As the NHNS and the CSLC share sampling unit blocks, we linked the survey databases using prefecture, area, unit block, household number, sex and age. Among 5607 subjects of the 2013 NHNS, 5337 were linked to the 2013 CSLC. The final sample used in the current analysis comprised 4658 men and women aged 20 years or older with complete information on the variables of interest.

\section{Dietary assessment}

Dietary intake data were collected using a $1 \mathrm{~d}$ semiweighed household dietary record on one optional day in November, excluding Sundays and national holidays. A detailed description of the procedure has been published elsewhere ${ }^{(28,29,31)}$. Briefly, during the orientation session before the survey, trained investigators (mainly dietitians and registered dietitians) gave household members who are usually responsible for food preparation (i.e. the main record-keeper) both written and verbal instructions on the study purpose and how to complete the dietary record. The subjects were instructed in the use of a scale to weigh each and every item of food and beverage consumed in the household prior to consumption and they were asked to record this information including food waste and leftovers in the recording form (although the equipment for weighing foods and beverages was not provided for the survey because of limited financial resources). When household members shared food from the same dish, the record-keeper was also asked to record approximate proportions of the food taken by each household member so that the dietary intake of each individual could be calculated. When weighing was not possible (e.g. eating out), the record-keeper was asked to record the size and quantity of foods they ate using household measures in as much detail as possible. When the trained investigators visited each home to collect the diet records, they checked the completeness of recording forms and, if necessary, corrected any missing and/or 


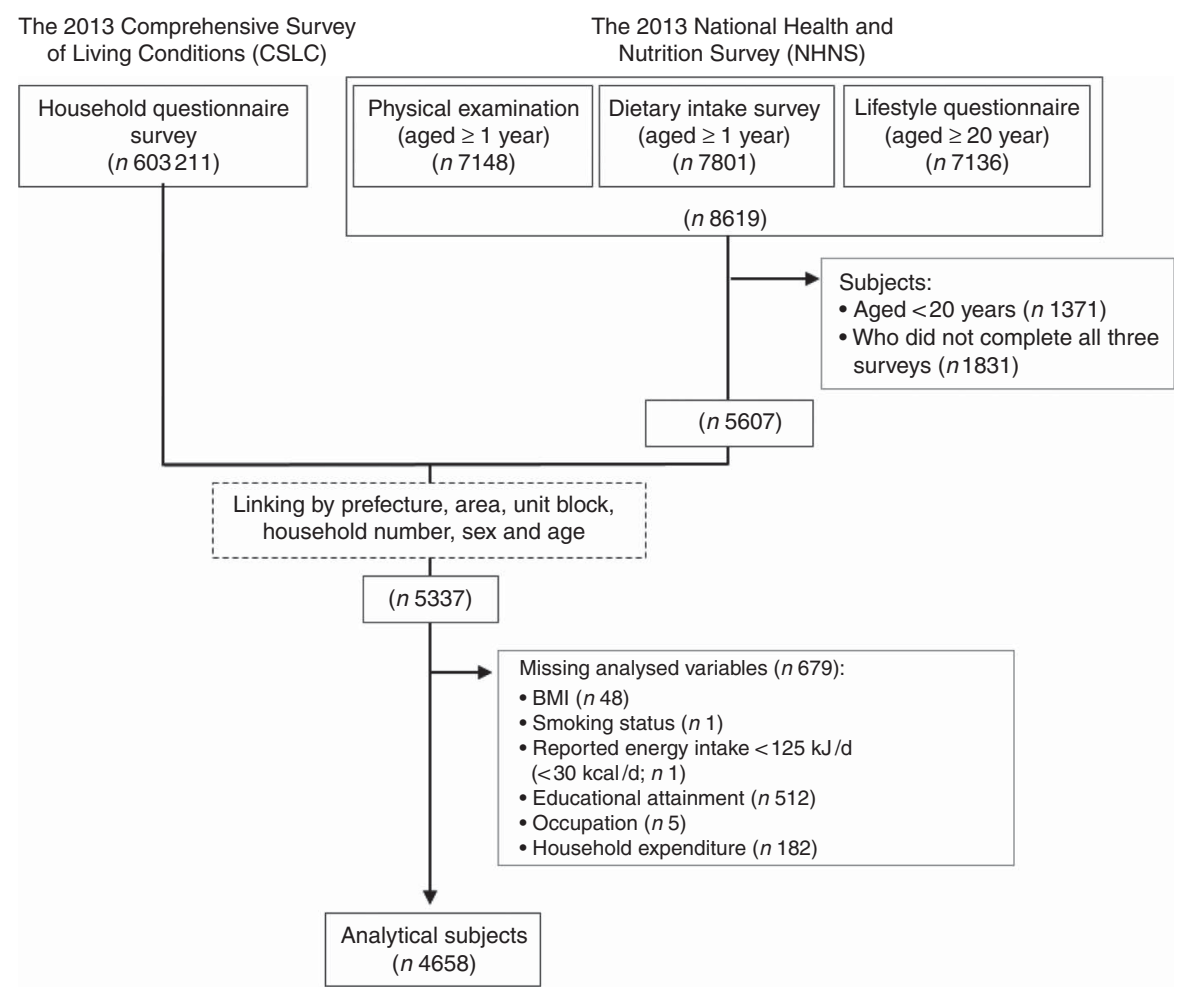

Fig. 1 Procedure for selecting subjects for the current analysis

illogical information. In accordance with a study manual of the NHNS, the trained investigators converted these estimates of portion sizes being recorded using household measures into weights that can then be used to calculate food and nutrient intakes. After all of the collected dietary records were checked at the local centre, trained investigators input dietary intake data using software specifically developed for this survey. Estimates of food and beverage items, energy and nutrients for each individual were calculated from the record of household food consumption and, for shared dishes or foods, the approximate proportion consumed by each household member, based on the Standard Tables of Food Composition in Japan ${ }^{(32)}$. Dietary energy density $(\mathrm{kJ} / \mathrm{g})$ was calculated by dividing total energy intake provided by the reported edible weight of food items only. Caloric and non-caloric beverages were excluded because beverages tend to water down the true energy density of the diet, which may lead to misinterpretation of the true exposure to a high-energydense $\operatorname{diet}^{(33,34)}$.

The validity of this household-based dietary record to estimate food and nutrient intakes at the individual level has been examined in Japan ${ }^{(31)}$. In a previous study of sixty-four female volunteers (female dietetic students and their mothers) in thirty-two households, dietary intakes among young women estimated by $1 \mathrm{~d}$ weighed household-based dietary record by their mothers were compared with those estimated by $1 \mathrm{~d}$ weighed individualbased dietary record, which was independently conducted by young women themselves. Mean differences between intakes estimated by the two methods were $6.2 \%$ for energy, $5.7 \%$ for protein, $6.7 \%$ for fat and $6.3 \%$ for carbohydrate, whereas Pearson correlation coefficients were 0.90 for energy, 0.89 for protein, 0.91 for total fat and $0 \cdot 90$ for carbohydrate.

\section{Monetary diet cost}

Monetary diet cost was estimated by linking the dietary data of the NHNS with retail food prices. The food prices were taken mainly from the National Retail Price Survey $2013^{(35)}$, which provides the average prices per $100 \mathrm{~g}$ portion of major food items. This survey is conducted annually in approximately 167 cities, towns and villages, and annual average prices were calculated as mean values of all survey areas, weighted for population size. To calculate monetary diet cost, food price values were assigned to each individual food and beverage item that appeared in the dietary record. Mixed dishes that were prepared from recipes were decomposed into ingredients. As information on foods that the subjects obtained from a restaurant or other food-service establishments was not collected in the NHNS, we could not consider the added costs associated with the preparation and service of foods and beverages consumed outside the home. The procedure for estimating costs was therefore based on the assumption that all foods and beverages were purchased at retail and prepared and eaten at home, in accordance with previous studies ${ }^{(15,21-23)}$. Calculations included 
correction for preparation and waste (e.g. trimming and peeling of vegetables and fruits, removal of bones and skin from fish).

Of the 1426 food and beverage items appearing in the dietary record, the National Retail Price Survey provided direct matches for 725 foods (50.8\%). For the 663 foods that could not be matched directly, price values for similar food items (e.g. same botanical group) were used as proxies $(46.5 \%)$. For the remaining thirty-eight items that had no price value and no comparable food in the National Retail Price Survey, prices (per $100 \mathrm{~g}$ ) from the websites of a nationally distributed supermarket (Seiyu, Japan) were used. When more than one price was available from the websites, a mean value was calculated. Promotional or sale prices were not used to determine costs. Monetary value of diets (Japanese yen/d) was calculated by multiplying the food price per edible $100 \mathrm{~g}$ by the amount of each food consumed by the respondent (g/d) (divided by 100), and then summing these values for each participant.

\section{Assessment of sociodemographic and lifestyle characteristics}

Because the NHNS has little information on socioeconomic status, information on sociodemographic and socio-economic variables was explored from the 2013 $\mathrm{CSLC}^{(27)}$. We obtained information on educational attainment ( $<13$ years (high school or less); 13-14 years (technical or professional school); $\geq 15$ years (university or more)), occupation (professional/manager; sales/service/clerical; security/transportation/labour; non-worker), marital status (married; unmarried; widowed; divorced), household size (1, 2, 3 or 4 and $\geq 5$ persons), housing tenure (owned/occupied; council/housing association; rented) and household expenditure in May as socioeconomic indicators. Equivalent household expenditure was calculated by dividing household expenditure in May by the square root of household size ${ }^{(36)}$ and then categorizing into thirds (low; middle; high). Six age categories were defined (20-29, 30-39, 40-49, 50-59, 60-69 and $\geq 70$ years). Residential blocks were grouped into six regions (Hokkaido and Tohoku; Kanto; Hokuriku and Tokai; Kinki; Chugoku and Shikoku; Kyushu). The residential areas were also grouped into three categories according to population size (metropolitan area; city with population $\geq 150000$; city with population <150000; hereafter referred to as 'size of residential area'). At the physical examination of the NHNS, height and weight were measured to the nearest $0 \cdot 1 \mathrm{~cm}$ and $0 \cdot 1 \mathrm{~kg}$, respectively, in light clothing without shoes. BMI $\left(\mathrm{kg} / \mathrm{m}^{2}\right)$ was calculated as weight (in kilograms) divided by height (in metres) squared. Weight status was defined based on BMI as follows: underweight $\left(<18.5 \mathrm{~kg} / \mathrm{m}^{2}\right)$, normal $(\geq 18.5$ to $\left.<25.0 \mathrm{~kg} / \mathrm{m}^{2}\right)$ and overweight $\left(\geq 25 \cdot 0 \mathrm{~kg} / \mathrm{m}^{2}\right)^{(37)}$. Information on smoking status (never; past; current) and physical activity (none; habitual) was collected from the lifestyle questionnaire of the NHNS ${ }^{(28)}$. Habitual physical activity was defined as doing at least $30 \mathrm{~min}$ of exercise twice weekly over the previous year, in accordance with the $\mathrm{NHNS}^{(28)}$.

\section{Statistical analysis}

All statistical analyses were performed using the SAS statistical software package version 9.4. All reported $P$ values are two-tailed and $P<0.05$ was considered to be statistically significant. Descriptive data were presented as mean and $95 \%$ confidence interval or as median and interquartile range for continuous variables, and as percentages of subjects for categorical variables. To avoid biased grouping due to variation in body size and energy requirement, nutrient and food intake values were energyadjusted using the density method (i.e. percentage of energy for energy-providing nutrients and amount per $4184 \mathrm{~kJ}$ ( $1000 \mathrm{kcal})$ of energy for other nutrients and foods). We used crude and energy-adjusted values by the density method (per $4184 \mathrm{~kJ}$ ) for monetary diet cost. Use of energy-adjusted values (for diet cost and dietary intake) by the residual method ${ }^{(38)}$ did not change the results materially (data not shown). All mean values of monetary diet cost (Japanese yen/d) and energy-adjusted diet cost (Japanese yen $/ 4184 \mathrm{~kJ}$ ) were calculated for the whole sample and for each category of the following sociodemographic and lifestyle variables: sex, age, residential block, size of residential area, educational attainment, occupation, marital status, housing tenure, equivalent monthly household expenditure, weight status, smoking status and physical activity. Differences in diet cost and energy-adjusted diet cost among categories of each variable were tested using univariate and multivariate regression analyses. Multivariate-adjusted diet cost was calculated by entering all variables simultaneously into a regression model to assess the independent associations between diet cost and sociodemographic and lifestyle characteristics.

Univariate and multiple linear regression analyses were performed to explore the associations of energy-adjusted diet cost with food and nutrient intakes. As a crude model, we calculated means for food and nutrient intakes and dietary energy density across the quintiles of energyadjusted diet cost. We controlled for the effects of the following potential confounders: sex, age, residential block, size of residential area, educational attainment, occupation, marital status, household size, housing tenure, equivalent monthly household expenditure, weight status, smoking status and physical activity (multivariate model). Tests for trend associations were performed by modelling the median value of each quintile category as a continuous variable. In addition, effect modification by sex and age was considered by adding interaction terms to the model. We also calculated the regression coefficient and 95\% confidence interval of the variation in dietary intake, which reflect the change in dietary intake per 100 Japanese yen increase in energy-adjusted diet cost. When 
energy-adjusted diet cost was consistently associated with food and nutrient intakes in both categorical and continuous form, we considered it to be statistically significant. As crude and multivariate models showed similar results, only the latter are shown in the present paper.

\section{Results}

\section{Characteristics of the study population}

Characteristics of the 4658 analytical subjects are shown in Table 1. Compared with other participants in the 2013 CSLC and NHNS ( $n$ 679), those included in the analyses were younger and of normal weight status, and less likely to live in Kanto or Kinki regions or in metropolitan areas, to have large household size, to have high monthly expenditure or to currently smoke (all $P<0 \cdot 05$ ). There were no differences in sex, educational attainment, occupation, marital status, housing tenure or physical activity between the subjects studied and the remaining participants.

\section{Associations of monetary value of diets with sociodemographic and lifestyle characteristics}

The mean monetary value of diets among Japanese adults was 1022 Japanese yen/d and the mean energy-adjusted monetary value was 525 Japanese yen/4184 kJ (1000 kcal). Both crude and energy-adjusted diet cost increased linearly with age $(P<0 \cdot 001)$.

In the univariate model, differences in crude and energy-adjusted diet cost were consistently observed across the categories of several sociodemographic and lifestyle variables, including sex, age, occupation, marital status, household size, housing tenure, equivalent monthly household expenditure, smoking status and physical activity. With some exceptions, similar results were also observed in the multivariate model. Older age, higher educational attainment, smaller household size, house owner/occupiers, higher equivalent monthly household expenditure and a habit of physical activity were clearly associated with higher diet cost and higher energyadjusted diet cost (all $P<0 \cdot 05$ ). In contrast, no independent associations were observed by marital status, weight status or smoking status in relation to diet cost or energyadjusted diet cost.

\section{Food contributors to monetary diet cost}

The relative contributions of different food groups to monetary diet cost are shown in Table 2. The principal food groups were vegetables, mushrooms and seaweed (18.4\%), meat (16.4\%), fish and shellfish (16.2\%), beverages $(12 \cdot 7 \%)$, grain $(11 \cdot 1 \%$; mainly rice $(7 \cdot 1 \%))$ and fruit $(6 \cdot 2 \%)$, contributing $\geq 80 \%$ to monetary diet cost per day. Differences in mean diet cost were observed in many food groups between different sex and age groups. The highest contributor to diet cost was meat for men (17.6\%) and the younger age group (20.3\%) and vegetables, mushrooms and seaweed for women (19.5\%) and the older age group (19.7\%).

\section{Associations between energy-adjusted diet cost and dietary intake}

Table 3 shows the cross-sectional associations of energyadjusted diet cost with dietary intake. Generally, similar results were consistently observed when energy-adjusted diet cost was treated as a categorical variable (quintile) and as a continuous variable, with the exception of energy and SFA intake. At the food level, energy-adjusted diet cost was positively associated with the consumption of pulses and nuts, vegetables, mushrooms and seaweed, fruit, fish and shellfish, meat, dairy products and beverages, and negatively associated with the consumption of grain (white rice, bread, noodles), eggs, and fats and oils (all $P$ for trend $<0 \cdot 001)$. At the nutrient level, energy-adjusted diet cost was positively associated with the intake of protein, alcohol, dietary fibre, cholesterol and all vitamins and minerals examined, and was negatively associated with the intake of carbohydrate (all $P$ for trend $<0.001$ ). Further, energy-adjusted diet cost was inversely associated with energy density ( $P$ for trend $<0 \cdot 01$ ). These associations were still evident after taking into account potential confounders, including sociodemographic and lifestyle factors. In contrast, no association was observed between energy-adjusted diet cost and whole grain, potatoes, sugars and confectioneries, or total fat.

We also conducted the same analyses for men and women and for younger and older age groups separately. Similar patterns of association were observed between energy-adjusted diet cost and dietary intake, and tests for interaction with sex or age were not significant (data not shown).

\section{Discussion}

The principal finding of the current cross-sectional study was that independent associations with monetary value of diets were evident for certain socio-economic indicators (i.e. educational attainment, equivalent monthly household expenditure and housing tenure). The second finding was that higher monetary value of diets was associated with favourable food and nutrient intake patterns, except for higher sodium, cholesterol and alcohol intake. These associations were still evident after adjustment for additional sociodemographic and lifestyle factors. To the best of our knowledge, the present study is the first to examine the relationships of diet cost to sociodemographic characteristics and food and nutrient intake pattern on the basis of data from a nationally representative survey in a non-Western population.

There is now a growing body of evidence from Western countries that higher monetary value of diets is consistently associated with healthier diets, including a higher intake 


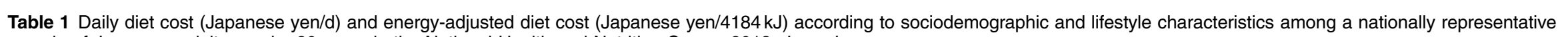
sample of Japanese adults aged $\geq 20$ years in the National Health and Nutrition Survey 2013, Japan $\dagger$

\begin{tabular}{|c|c|c|c|c|c|c|c|c|c|c|c|c|c|c|}
\hline & \multirow[b]{3}{*}{$n$} & \multirow[b]{3}{*}{$\%$} & \multicolumn{6}{|c|}{ Univariate model } & \multicolumn{6}{|c|}{ Multivariate model } \\
\hline & & & \multicolumn{3}{|c|}{$\begin{array}{c}\text { Diet cost } \\
\text { (Japanese yen/d) }\end{array}$} & \multicolumn{3}{|c|}{$\begin{array}{l}\text { Energy-adjusted diet cost } \\
\text { (Japanese yen/4184 kJ) }\end{array}$} & \multicolumn{3}{|c|}{$\begin{array}{c}\text { Diet cost } \\
\text { (Japanese yen/d) }\end{array}$} & \multicolumn{3}{|c|}{$\begin{array}{l}\text { Energy-adjusted diet cost } \\
\text { (Japanese yen/4184 kJ) }\end{array}$} \\
\hline & & & Mean & $95 \% \mathrm{Cl}$ & $P$ value $\neq$ & Mean & $95 \% \mathrm{Cl}$ & $P$ value $\ddagger$ & Mean & $95 \% \mathrm{Cl}$ & $P$ value $\S$ & Mean & $95 \% \mathrm{Cl}$ & $P$ value $\S$ \\
\hline Total & 4658 & $100 \cdot 0$ & 1022 & 1011,1033 & - & 525 & 521,530 & - & - & - & - & - & - & - \\
\hline \multicolumn{15}{|l|}{ Sex } \\
\hline Male & 2115 & $45 \cdot 4$ & 1132 & 1114,1150 & $<0.001$ & 513 & 507,519 & $<0.001$ & 1117 & 1099,1134 & $<0.001$ & 509 & 502,515 & $<0.001$ \\
\hline Female & 2543 & 54.6 & 930 & 917,944 & & 535 & 530,541 & & 943 & 927,959 & & 539 & 534,545 & \\
\hline \multicolumn{15}{|l|}{ Age } \\
\hline $20-29$ years & 377 & $8 \cdot 1$ & 923 & 887, 959 & $<0.001$ & 468 & 456,481 & $<0.001$ & 935 & 889,980 & $<0.001$ & 471 & 454,488 & $<0.001$ \\
\hline 30-39 years & 590 & $12 \cdot 7$ & 924 & 894,954 & & 482 & 471,493 & & 951 & 918,984 & & 486 & 474,498 & \\
\hline $40-49$ years & 720 & $15 \cdot 5$ & 936 & 910,962 & & 484 & 475,493 & & 956 & 927,986 & & 488 & 477,498 & \\
\hline $50-59$ years & 707 & $15 \cdot 2$ & 1029 & 1001,1058 & & 521 & 512,531 & & 1016 & 987,1044 & & 518 & 508,529 & \\
\hline $60-69$ years & 1011 & $21 \cdot 7$ & 1134 & 1108,1160 & & 563 & 554,572 & & 1114 & 1090,1138 & & 558 & 549,567 & \\
\hline$\geq 70$ years & 1253 & $26 \cdot 9$ & 1052 & 1030,1074 & & 559 & 550,567 & & 1048 & 1022,1075 & & 560 & 550,569 & \\
\hline \multicolumn{15}{|l|}{ Residential block } \\
\hline Hokkaido and Tohoku & 608 & $13 \cdot 1$ & 1006 & 974,1038 & 0.01 & 527 & 516,539 & 0.08 & 1008 & 979,1038 & 0.01 & 526 & 515,537 & 0.03 \\
\hline Kanto & 1403 & $30 \cdot 1$ & 1037 & 1016,1057 & & 525 & 517,532 & & 1030 & 1010,1050 & & 525 & 518,533 & \\
\hline Hokuriku and Tokai & 855 & 18.4 & 1005 & 979,1032 & & 532 & 522,543 & & 1019 & 995,1044 & & 535 & 526,544 & \\
\hline Kinki & 741 & $15 \cdot 9$ & 1060 & 1031,1090 & & 532 & 522,543 & & 1058 & 1031,1085 & & 531 & 521,541 & \\
\hline Chugoku and Shikoku & 476 & $10 \cdot 2$ & 994 & 959,1029 & & 517 & 505,530 & & 977 & 943,1010 & & 512 & 499,524 & \\
\hline Kyushu & 575 & $12 \cdot 3$ & 1002 & 970,1034 & & 513 & 502,524 & & 1011 & 981,1042 & & 516 & 505,528 & \\
\hline \multicolumn{15}{|l|}{ Size of residential area } \\
\hline Metropolitan area & 951 & $20 \cdot 4$ & 1027 & 1002, 1052 & 0.29 & 536 & 527,546 & 0.002 & 1021 & 997,1045 & 0.06 & 533 & 524,542 & 0.004 \\
\hline City with population $\geq 150000$ & 1687 & $36 \cdot 2$ & 1010 & 992,1028 & & 517 & 510,523 & & 1005 & 988,1023 & & 517 & 510,523 & \\
\hline City with population $<150000$ & 2020 & 43.4 & 1030 & 1012,1047 & & 528 & 521,534 & & 1036 & 1019,1053 & & 529 & 523,536 & \\
\hline \multicolumn{15}{|l|}{ Educational attainment } \\
\hline$<13$ years & 2857 & $61 \cdot 3$ & 1008 & 993, 1022 & $<0.001$ & 526 & 521,531 & 0.77 & 1000 & 986,1014 & $<0.001$ & 517 & 512,522 & $<0.001$ \\
\hline $13-14$ years & 815 & 17.5 & 993 & 967,1019 & & 522 & 513,531 & & 1057 & 1031,1084 & & 534 & 524,543 & \\
\hline$\geq 15$ years & 986 & $21 \cdot 2$ & 1087 & 1061,1112 & & 526 & 517,535 & & 1056 & 1032,1081 & & 543 & 534,552 & \\
\hline \multicolumn{15}{|l|}{ Occupation } \\
\hline Professional/manager & 708 & $15 \cdot 2$ & 1066 & 1036,1096 & $<0.001$ & 521 & 510,531 & $<0.001$ & 1035 & 1006,1064 & 0.41 & 532 & 521,543 & 0.003 \\
\hline Sales/service/clerical & 1139 & 24.5 & 971 & 949,993 & & 516 & 507,524 & & 1025 & 1003,1048 & & 535 & 526,543 & \\
\hline Security/transportation/labour & 697 & $15 \cdot 0$ & 1055 & 1026,1084 & & 487 & 478,496 & & 1037 & 1008,1067 & & 510 & 499,521 & \\
\hline Non-worker & 2114 & 45.4 & 1024 & 1007,1041 & & 545 & 539,551 & & 1011 & 993,1028 & & 523 & 517,530 & \\
\hline \multicolumn{15}{|l|}{ Marital status } \\
\hline Married & 3324 & 71.4 & 1039 & 1026,1053 & $<0.001$ & 530 & 525,535 & $<0.001$ & 1025 & 1011,1038 & $0 \cdot 16$ & 526 & 521,531 & 0.46 \\
\hline Unmarried & 724 & $15 \cdot 5$ & 986 & 958,1014 & & 493 & 483,504 & & 1035 & 1002,1068 & & 530 & 518,542 & \\
\hline Widowed & 400 & $8 \cdot 6$ & 964 & 927,1001 & & 552 & 538,566 & & 976 & 934,1018 & & 515 & 500,531 & \\
\hline Divorced & 210 & 4.5 & 982 & 926,1037 & & 515 & 496,534 & & 1021 & 969,1074 & & 519 & 499,538 & \\
\hline \multicolumn{15}{|l|}{ Household size } \\
\hline 1 person & 481 & $10 \cdot 3$ & 1040 & 1004,1076 & $<0.001$ & 536 & 522,551 & $<0.001$ & 1085 & 1045,1125 & $<0.001$ & 540 & 525,555 & $<0.001$ \\
\hline 2 people & 1501 & $32 \cdot 2$ & 1108 & 1087,1129 & & 558 & 551,566 & & 1078 & 1058,1098 & & 541 & 534,549 & \\
\hline 3 or 4 people & 2089 & 44.9 & 985 & 969,1001 & & 510 & 504,516 & & 990 & 974,1007 & & 517 & 511,523 & \\
\hline$\geq 5$ people & 587 & $12 \cdot 6$ & 919 & 892,946 & & 488 & 479,497 & & 939 & 908,971 & & 503 & 491,514 & \\
\hline
\end{tabular}


Table 1 Continued

\begin{tabular}{|c|c|c|c|c|c|c|c|c|c|c|c|c|c|c|}
\hline & \multirow[b]{3}{*}{$n$} & \multirow[b]{3}{*}{$\%$} & \multicolumn{6}{|c|}{ Univariate model } & \multicolumn{6}{|c|}{ Multivariate model } \\
\hline & & & \multicolumn{3}{|c|}{$\begin{array}{c}\text { Diet cost } \\
\text { (Japanese yen/d) }\end{array}$} & \multicolumn{3}{|c|}{$\begin{array}{l}\text { Energy-adjusted diet cost } \\
\text { (Japanese yen/4184 kJ) }\end{array}$} & \multicolumn{3}{|c|}{$\begin{array}{c}\text { Diet cost } \\
\text { (Japanese yen/d) }\end{array}$} & \multicolumn{3}{|c|}{$\begin{array}{l}\text { Energy-adjusted diet cost } \\
\text { (Japanese yen/4184 kJ) }\end{array}$} \\
\hline & & & Mean & $95 \% \mathrm{Cl}$ & $P$ value $\ddagger$ & Mean & $95 \% \mathrm{Cl}$ & $P$ value $\ddagger$ & Mean & $95 \% \mathrm{Cl}$ & $P$ value§ & Mean & $95 \% \mathrm{Cl}$ & $P$ value§ \\
\hline \multicolumn{15}{|l|}{ Housing tenure } \\
\hline Owned/occupied & 3729 & $80 \cdot 1$ & 1042 & 1029,1055 & $<0.001$ & 532 & 527,537 & $<0.001$ & 1041 & 1029,1053 & $<0.001$ & 530 & 525,534 & $<0.001$ \\
\hline Council/housing association & 436 & 9.4 & 960 & 922,999 & & 505 & 491,518 & & 964 & 929,1000 & & 513 & 499,526 & \\
\hline Rented & 493 & $10 \cdot 6$ & 924 & 891,956 & & 494 & 481,507 & & 928 & 893,962 & & 504 & 491,517 & \\
\hline \multicolumn{15}{|l|}{ Equivalent household expenditure } \\
\hline Low ( $<106000$ Japanese yen) & 1566 & $33 \cdot 6$ & 966 & 947,985 & $<0.001$ & 503 & 496,510 & $<0.001$ & 981 & 963,1000 & $<0.001$ & 508 & 501,515 & $<0.001$ \\
\hline Middle (107 000-155000 Japanese yen) & 1540 & $33 \cdot 1$ & 1014 & 995,1033 & & 526 & 519,533 & & 1021 & 1003,1040 & & 528 & 521,535 & \\
\hline High ( $\geq 156000$ Japanese yen) & 1552 & $33 \cdot 3$ & 1086 & 1066,1107 & & 547 & 540,555 & & 1064 & 1045,1082 & & 541 & 534,548 & \\
\hline \multicolumn{15}{|l|}{ Weight status } \\
\hline Underweight & 406 & 8.7 & 940 & 904,976 & $<0.001$ & 525 & 511,539 & 0.66 & 993 & 957,1029 & 0.11 & 525 & 512,539 & 0.83 \\
\hline Normal & 3138 & $67 \cdot 4$ & 1020 & 1006,1033 & & 524 & 519,529 & & 1020 & 1007,1033 & & 525 & 520,529 & \\
\hline Overweight & 1114 & 23.9 & 1058 & 1033,1083 & & 529 & 520,537 & & 1038 & 1016,1059 & & 528 & 520,536 & \\
\hline \multicolumn{15}{|l|}{ Smoking status } \\
\hline Non-smoker & 3483 & 74.8 & 1009 & 996,1022 & $<0.001$ & 531 & 526,536 & $<0.001$ & 1023 & 1011,1036 & 0.06 & 525 & 520,530 & 0.40 \\
\hline Past smoker & 344 & 7.4 & 1128 & 1083,1173 & & 530 & 515,545 & & 1057 & 1018,1097 & & 535 & 520,550 & \\
\hline Current smoker & 831 & $17 \cdot 8$ & 1033 & 1005,1062 & & 500 & 490,510 & & 1001 & 974,1028 & & 523 & 514,533 & \\
\hline \multicolumn{15}{|l|}{ Physical activity } \\
\hline None & 3739 & $80 \cdot 3$ & 1000 & 987,1012 & $<0.001$ & 519 & 514,523 & $<0.001$ & 1011 & 1000,1023 & $<0.001$ & 523 & 519,528 & 0.04 \\
\hline Habitual & 919 & $19 \cdot 7$ & 1112 & 1084,1139 & & 553 & 543,563 & & 1065 & 1040,1089 & & 534 & 525,543 & \\
\hline
\end{tabular}

†100 Japanese yen $=0.64$ Pound Sterling, 0.75 Euros and 1.02 US dollars in November 2013.

$\ddagger P$ values for difference were calculated for sex, residential area and marital status and $P$ values for trend were calculated by the linear trend test for the other variables.

§For analysis of diet cost and energy-adjusted diet cost of each sociodemographic variable, adjustment was made for all other sociodemographic variables shown in the table. 
Table 2 Contribution of food groups to monetary diet cost (Japanese yen/d) among Japanese adults aged $\geq 20$ years in the National Health and Nutrition Survey 2013, Japan†

\begin{tabular}{|c|c|c|c|c|c|c|c|c|c|c|c|c|c|c|c|c|c|c|}
\hline & & & & & & & \multicolumn{6}{|c|}{ Sex } & \multicolumn{6}{|c|}{ Age } \\
\hline & & & & \multicolumn{3}{|c|}{ All $(n$ 4658) } & \multicolumn{3}{|c|}{ Men $(n 2115)$} & \multicolumn{3}{|c|}{ Women ( $n$ 2543) } & \multicolumn{3}{|c|}{$20-59$ years $(n$ 2394) } & \multicolumn{3}{|c|}{$\geq 60$ years $(n 2264)$} \\
\hline & \multicolumn{3}{|c|}{$\begin{array}{l}\text { Cost of food group } \ddagger \\
\text { (Japanese yen/100 g) }\end{array}$} & \multicolumn{2}{|c|}{$\begin{array}{c}\text { Diet cost } \\
\text { (Japanese yen/d) }\end{array}$} & \multirow[b]{2}{*}{$\%$} & \multicolumn{2}{|c|}{$\begin{array}{c}\text { Diet cost } \\
\text { (Japanese yen/d) }\end{array}$} & \multirow[b]{2}{*}{$\%$} & \multicolumn{2}{|c|}{$\begin{array}{c}\text { Diet cost } \\
\text { (Japanese yen/d) }\end{array}$} & \multirow[b]{2}{*}{$\%$} & \multicolumn{2}{|c|}{$\begin{array}{c}\text { Diet cost } \\
\text { (Japanese yen/d) }\end{array}$} & \multirow[b]{2}{*}{$\%$} & \multicolumn{2}{|c|}{$\begin{array}{c}\text { Diet cost } \\
\text { (Japanese yen/d) }\end{array}$} & \multirow[b]{2}{*}{$\%$} \\
\hline & $n$ & Median & IQR & Mean & $95 \% \mathrm{Cl}$ & & Mean & $95 \% \mathrm{Cl}$ & & Mean§ & $95 \% \mathrm{Cl}$ & & Mean & $95 \% \mathrm{Cl}$ & & Mean§ & $95 \% \mathrm{Cl}$ & \\
\hline $\begin{array}{l}\text { Total monetary diet cost } \\
\text { Cost of each food group }\end{array}$ & - & - & - & 1022 & 1011,1033 & - & 1132 & 1114,1150 & - & 930 & 917,944 & - & 959 & 944,974 & - & 1089 & 1072,1106 & - \\
\hline $\begin{array}{l}\text { Vegetables, mushrooms } \\
\text { and seaweed }\end{array}$ & 323 & 93 & $71-159$ & 188 & 184,192 & $18 \cdot 4$ & 196 & 190, 201 & $17 \cdot 3$ & $182^{\star \star *}$ & 177,186 & 19.5 & 162 & 158,167 & $16 \cdot 9$ & $215^{\star \star \star}$ & 209,221 & $19 \cdot 7$ \\
\hline Meat & 112 & 199 & $127-234$ & 167 & 163,172 & $16 \cdot 4$ & 199 & 192, 207 & $17 \cdot 6$ & $141^{\star \star *}$ & 135,146 & $15 \cdot 1$ & 194 & 188,201 & $20 \cdot 3$ & $139^{\star \star *}$ & 133,145 & $12 \cdot 7$ \\
\hline Fish and shellfish & 277 & 189 & $149-356$ & 165 & 160,171 & $16 \cdot 2$ & 186 & 177, 194 & $16 \cdot 4$ & $148^{\star \star *}$ & 142,155 & $15 \cdot 9$ & 131 & 125,137 & 13.7 & $202^{* \star *}$ & 193,210 & 18.5 \\
\hline Beverages & 75 & 20 & $12-89$ & 130 & 126,134 & 12.7 & 172 & 165,180 & $15 \cdot 2$ & $95^{\star \star *}$ & 92,99 & $10 \cdot 2$ & 131 & 125,137 & $13 \cdot 6$ & 129 & 124,135 & 11.9 \\
\hline Alcoholic beverages & 24 & 71 & $49-135$ & 54 & 50,58 & $5 \cdot 3$ & 94 & 87,101 & 8.3 & $21^{\star \star \star}$ & 18,24 & $2 \cdot 3$ & 55 & 49,60 & 5.7 & 53 & 48,58 & 4.9 \\
\hline Soft drinks & 34 & 16 & $12-20$ & 13 & 12,15 & 1.3 & 18 & 15,20 & 1.6 & $10^{\star \star \star}$ & 9,11 & $1 \cdot 1$ & 16 & 14,18 & 1.7 & $11^{\star \star \star}$ & 9,12 & 1.0 \\
\hline $\begin{array}{l}\text { Non-energy-containing } \\
\text { beverages }\end{array}$ & 17 & 15 & $12-510$ & 63 & 61,64 & $6 \cdot 1$ & 61 & 58,63 & $5 \cdot 4$ & $64^{*}$ & 62,66 & 6.9 & 60 & 58,62 & $6 \cdot 2$ & $66^{\star \star \star}$ & 64,68 & 6.0 \\
\hline Grain & 103 & 22 & $20-45$ & 114 & 112,115 & $11 \cdot 1$ & 134 & 131,136 & 11.8 & $97^{\star \star \star}$ & 96,99 & 10.5 & 120 & 118,123 & $12 \cdot 5$ & $107^{\star \star \star}$ & 105,109 & 9.8 \\
\hline White rice & 13 & 21 & $20-73$ & 72 & 71,73 & $7 \cdot 1$ & 88 & 86,90 & 7.7 & $59^{\star \star \star}$ & 58,61 & $6 \cdot 3$ & 75 & 73,77 & 7.8 & $69^{\star \star \star}$ & 68,71 & 6.4 \\
\hline Noodles & 30 & 22 & $16-52$ & 19 & 18,21 & 1.9 & 24 & 22,26 & $2 \cdot 1$ & $16^{\star \star \star}$ & 15,17 & 1.7 & 23 & 21,25 & 2.4 & $16^{\star * *}$ & 14,17 & 1.4 \\
\hline Bread & 10 & 40 & $40-40$ & 14 & 14,15 & 1.4 & 14 & 13,14 & 1.2 & $15^{\star \star}$ & 14,16 & 1.6 & 14 & 14,15 & 1.5 & 15 & 14,15 & 1.3 \\
\hline Others & 17 & 31 & $21-73$ & 4 & 3,4 & 0.4 & 4 & 3,4 & 0.3 & 3 & 3,4 & 0.4 & 4 & 4,5 & 0.5 & $3^{* * *}$ & 2,3 & 0.3 \\
\hline Whole grain & 33 & 21 & $19-22$ & 4 & 4,5 & 0.4 & 5 & 4,6 & 0.4 & $4^{\star}$ & 3,4 & 0.4 & 4 & 3,5 & 0.4 & $5^{\star}$ & 4,6 & 0.5 \\
\hline Fruits & 78 & 60 & $26-94$ & 63 & 61,66 & 6.2 & 57 & 54,60 & 5.0 & $69^{\star \star \star}$ & 66,72 & 7.4 & 37 & 35,40 & 3.9 & $91^{\star \star *}$ & 87,94 & $8 \cdot 3$ \\
\hline Sugars and confectioneries & 158 & 121 & $100-141$ & 51 & 49,54 & $5 \cdot 0$ & 46 & 42,49 & 4.0 & $56^{\star \star \star}$ & 52,59 & $6 \cdot 0$ & 51 & 47,55 & $5 \cdot 3$ & 52 & 48,55 & 4.8 \\
\hline Dairy products & 35 & 161 & $59-316$ & 42 & 40,44 & $4 \cdot 1$ & 37 & 35,39 & 3.3 & $46^{\star \star \star}$ & 44,48 & 4.9 & 38 & 36,40 & 3.9 & $47^{\star \star \star}$ & 44,49 & 4.3 \\
\hline Pulses and nuts & 85 & 79 & $52-113$ & 31 & 30,32 & 3.0 & 32 & 31,34 & 2.9 & $30^{\star *}$ & 29,31 & 3.2 & 27 & 25,28 & 2.8 & $36^{\star \star \star}$ & 34,37 & 3.3 \\
\hline Seasoning & 118 & 54 & $28-218$ & 31 & 30,31 & 3.0 & 33 & 32,34 & 2.9 & $29^{\star \star \star}$ & 28,30 & 3.1 & 31 & 30,32 & 3.2 & 31 & 30,31 & $2 \cdot 8$ \\
\hline Potatoes & 32 & 37 & $21-72$ & 22 & 21,22 & $2 \cdot 1$ & 22 & 21,23 & 1.9 & 21 & 20,22 & $2 \cdot 3$ & 18 & 17,19 & 1.9 & $25^{\star \star \star}$ & 24,26 & $2 \cdot 3$ \\
\hline Eggs & 10 & 35 & $31-61$ & 11 & 11,11 & $1 \cdot 1$ & 12 & 11,12 & 1.0 & $10^{\star \star \star *}$ & 10,10 & $1 \cdot 1$ & 11 & 11,11 & 1.1 & 11 & 10,11 & 1.0 \\
\hline Fats and oils & 19 & 75 & $32-100$ & 7 & 6.7 & 0.6 & 7 & 7,7 & 0.6 & $6^{\star \star}$ & 6,6 & 0.7 & 7 & 7,8 & 0.7 & $6^{\star \star \star}$ & 6,6 & 0.5 \\
\hline
\end{tabular}

IQR, interquartile range.

†100 Japanese yen $=0.64$ Pound Sterling, 0.75 Euros and 1.02 US dollars in November 2013.

$\ddagger$ Median (IQR) of food cost for each food group that appeared in the $1 \mathrm{~d}$ semi-weighed dietary record among 4658 Japanese adults aged 20 years or older.

$\S P$ values for difference in mean value of food cost between subgroups (sex and age groups) were calculated by Student's $t$ test $\left({ }^{\star} P<0.05,{ }^{\star \star} P<0.01,{ }^{\star \star \star} P<0.001\right.$ ). 
Table 3 Association of food and nutrient intakes with energy-adjusted monetary diet cost among Japanese adults aged $\geq 20$ years in the National Health and Nutrition Survey 2013 , Japan†

\begin{tabular}{|c|c|c|c|c|c|c|c|c|c|c|c|c|c|c|c|}
\hline & \multirow[b]{4}{*}{ Unit } & \multicolumn{10}{|c|}{ Quintile of energy-adjusted diet cost (Japanese yen/4184 kJ) $\ddagger$} & \multirow{4}{*}{$\begin{array}{l}P \text { for } \\
\text { trendll }\end{array}$} & & & \\
\hline & & \multirow{2}{*}{\multicolumn{2}{|c|}{$\frac{\mathrm{Q} 1(n \text { 931) }}{368(135 \cdot 8-409 \cdot 9) \S}$}} & \multirow{2}{*}{\multicolumn{2}{|c|}{$\frac{\text { Q2 }(n \text { 932) }}{443(410 \cdot 0-475 \cdot 8) \S}$}} & \multirow{2}{*}{\multicolumn{2}{|c|}{$\frac{\text { Q3 }(n \text { 932) }}{508(475.9-539.0) \S}$}} & \multirow{2}{*}{\multicolumn{2}{|c|}{$\frac{\mathrm{Q} 4(n \text { 932) }}{576(539 \cdot 1-621 \cdot 4) \S}$}} & \multirow{2}{*}{\multicolumn{2}{|c|}{$\frac{\mathrm{Q} 5(n \text { 931) }}{701(621.5-1799) \S}$}} & & \multirow{2}{*}{\multicolumn{3}{|c|}{$\begin{array}{c}\text { Effect per } 100 \text { Japanese yen/ } \\
4184 \mathrm{~kJ} \text { increase }\end{array}$}} \\
\hline & & & & & & & & & & & & & & & \\
\hline & & Mean & $95 \% \mathrm{Cl}$ & Mean & $95 \% \mathrm{Cl}$ & Mean & $95 \% \mathrm{Cl}$ & Mean & $95 \% \mathrm{Cl}$ & Mean & $95 \% \mathrm{Cl}$ & & $\beta \pi$ & $95 \% \mathrm{Cl}$ & $P$ value \\
\hline \multicolumn{16}{|l|}{ Food intake } \\
\hline Grain & $\mathrm{g} / 4184 \mathrm{~kJ}$ & 281 & 276,285 & 245 & 240,249 & 225 & 220,229 & 211 & 207,216 & 195 & 190, 199 & $<0.001$ & $-20 \cdot 3$ & $-21 \cdot 7,-18 \cdot 8$ & $<0.001$ \\
\hline White rice & $\mathrm{g} / 4184 \mathrm{~kJ}$ & 198 & 192, 203 & 173 & 168,179 & 160 & 155,165 & 149 & 144,154 & 138 & 133,143 & $<0.001$ & -13.9 & $-15 \cdot 5,-12 \cdot 2$ & $<0.001$ \\
\hline Bread & $\mathrm{g} / 4184 \mathrm{~kJ}$ & 23 & 21,24 & 21 & 19, 22 & 20 & 19, 22 & 19 & 17,20 & 16 & 15,18 & $<0.001$ & -1.6 & $-2 \cdot 1,-1 \cdot 1$ & $<0.001$ \\
\hline Noodles & $\mathrm{g} / 4184 \mathrm{~kJ}$ & 48 & 44,52 & 38 & 34,42 & 32 & 29,36 & 32 & 28,36 & 28 & 24,32 & $<0.001$ & -4.9 & $-6 \cdot 2,-3 \cdot 7$ & $<0.001$ \\
\hline Others & $\mathrm{g} / 4184 \mathrm{~kJ}$ & 4.8 & $4 \cdot 1,5 \cdot 5$ & 4.4 & $3 \cdot 7,5 \cdot 0$ & $5 \cdot 2$ & $4 \cdot 6,5 \cdot 9$ & $4 \cdot 2$ & $3.5,4.8$ & 4.0 & $3 \cdot 3,4 \cdot 7$ & 0.27 & -0.2 & $-0.4,0.0$ & 0.10 \\
\hline Whole grain & $\mathrm{g} / 4184 \mathrm{~kJ}$ & 7.5 & $5.5,9.5$ & $8 \cdot 1$ & $6 \cdot 1,10 \cdot 1$ & $7 \cdot 3$ & $5 \cdot 3,9 \cdot 2$ & 7.5 & $5 \cdot 5,9.5$ & 8.9 & $6 \cdot 9,10 \cdot 9$ & 0.74 & 0.3 & $-0.4,0.9$ & 0.38 \\
\hline Potatoes & $\mathrm{g} / 4184 \mathrm{~kJ}$ & 26 & 24,29 & 27 & 25,29 & 28 & 26,30 & 28 & 26,30 & 28 & 26,30 & 0.30 & 0.3 & $-0.3,1 \cdot 0$ & 0.33 \\
\hline Pulses and nuts & $\mathrm{g} / 4184 \mathrm{~kJ}$ & 29 & 26,32 & 34 & 31,36 & 36 & 33,39 & 37 & 35,40 & 39 & 36,41 & $<0.001$ & $2 \cdot 7$ & $1 \cdot 8,3 \cdot 5$ & $<0.001$ \\
\hline $\begin{array}{l}\text { Vegetables, mushrooms } \\
\text { and seaweed }\end{array}$ & $\mathrm{g} / 4184 \mathrm{~kJ}$ & 113 & 107,118 & 149 & 143,154 & 163 & 157,168 & 183 & 178,189 & 217 & 211,222 & $<0.001$ & $25 \cdot 5$ & $23 \cdot 7,22 \cdot 5$ & $<0.001$ \\
\hline Fruits & $\mathrm{g} / 4184 \mathrm{~kJ}$ & 38 & 34,43 & 50 & 46,54 & 59 & 55,63 & 72 & 68,76 & 78 & 74,82 & $<0.001$ & $9 \cdot 2$ & $7 \cdot 9,10 \cdot 5$ & $<0.001$ \\
\hline Fish and shellfish & $\mathrm{g} / 4184 \mathrm{~kJ}$ & 23 & 21,25 & 34 & 32,36 & 39 & 37,42 & 46 & 44,48 & 62 & 60,64 & $<0.001$ & $10 \cdot 2$ & $9 \cdot 5,10 \cdot 8$ & $<0.001$ \\
\hline Meat & $\mathrm{g} / 4184 \mathrm{~kJ}$ & 35 & 33,37 & 41 & 39,43 & 44 & 42,46 & 48 & 46,50 & 50 & 48,52 & $<0.001$ & $3 \cdot 3$ & $2 \cdot 6,4 \cdot 0$ & $<0.001$ \\
\hline Eggs & $\mathrm{g} / 4184 \mathrm{~kJ}$ & 19 & 18,20 & 20 & 18,21 & 18 & 17,19 & 16 & 15,17 & 17 & 16,18 & $<0.001$ & $-1 \cdot 0$ & $-1 \cdot 4,-0 \cdot 6$ & $<0.001$ \\
\hline Dairy products & $\mathrm{g} / 4184 \mathrm{~kJ}$ & 41 & 37,45 & 49 & 45,53 & 52 & 48,56 & 54 & 50,58 & 55 & 51,59 & $<0.001$ & $3 \cdot 3$ & $2 \cdot 0,4 \cdot 6$ & $<0.001$ \\
\hline Fats and oils & $\mathrm{g} / 4184 \mathrm{~kJ}$ & $6 \cdot 1$ & $5 \cdot 8,6 \cdot 4$ & $5 \cdot 7$ & $5 \cdot 4,6 \cdot 0$ & $5 \cdot 2$ & $4 \cdot 9,5 \cdot 5$ & $4 \cdot 8$ & $4 \cdot 6,5 \cdot 1$ & $4 \cdot 3$ & $4 \cdot 0,4 \cdot 6$ & $<0.001$ & -0.4 & $-0.5,-0.3$ & $<0.001$ \\
\hline Sugars and confectioneries & $\mathrm{g} / 4184 \mathrm{~kJ}$ & 21 & 19,23 & 22 & 20,24 & 22 & 20,24 & 21 & 19,23 & 22 & 20,23 & 0.94 & 0.1 & $-0.6,0.7$ & 0.83 \\
\hline Beverages & $\mathrm{g} / 4184 \mathrm{~kJ}$ & 260 & 245,276 & 301 & 285,316 & 354 & 339,370 & 400 & 385,416 & 492 & 477,508 & $<0.001$ & 57.5 & $52 \cdot 5,62 \cdot 3$ & $<0.001$ \\
\hline Alcoholic beverages & $\mathrm{g} / 4184 \mathrm{~kJ}$ & 11 & 3,18 & 31 & 24,39 & 59 & 51,66 & 72 & 64,79 & 99 & 91,106 & $<0.001$ & $21 \cdot 1$ & $18 \cdot 6,23 \cdot 5$ & $<0.001$ \\
\hline Soft drinks & $\mathrm{g} / 4184 \mathrm{~kJ}$ & 25 & 21,30 & 22 & 18,27 & 26 & 21,31 & 27 & 22,32 & 27 & 23,32 & 0.46 & 1.4 & $-0.1,2 \cdot 9$ & 0.07 \\
\hline $\begin{array}{l}\text { Non-energy-containing } \\
\text { beverages }\end{array}$ & $\mathrm{g} / 4184 \mathrm{~kJ}$ & 224 & 210,239 & 247 & 232,261 & 270 & 255,284 & 302 & 287,316 & 366 & 352,381 & $<0.001$ & $35 \cdot 0$ & $30 \cdot 3,39 \cdot 6$ & $<0.001$ \\
\hline \multicolumn{16}{|l|}{ Nutrient intake } \\
\hline Protein & $\%$ of energy & $12 \cdot 9$ & $12 \cdot 7,13$ & $14 \cdot 4$ & $14 \cdot 2,14 \cdot 5$ & $15 \cdot 0$ & $14 \cdot 8,15 \cdot 2$ & $15 \cdot 7$ & $15 \cdot 5,15 \cdot 9$ & $17 \cdot 1$ & $16 \cdot 9,17 \cdot 3$ & $<0.001$ & 1.03 & $0.97,1.09$ & $<0.001$ \\
\hline Total fat & $\%$ of energy & $26 \cdot 0$ & $25 \cdot 6,26 \cdot 5$ & $26 \cdot 7$ & $26 \cdot 2,27 \cdot 2$ & $26 \cdot 4$ & $25 \cdot 9,26 \cdot 9$ & $26 \cdot 4$ & $25 \cdot 9,26 \cdot 9$ & $26 \cdot 1$ & $25 \cdot 6,26 \cdot 5$ & 0.63 & 0.01 & $-0.15,0.16$ & 0.94 \\
\hline SFA & $\%$ of energy & $7 \cdot 1$ & $7,7 \cdot 3$ & 7.4 & $7 \cdot 2,7.5$ & $7 \cdot 3$ & $7 \cdot 1,7 \cdot 5$ & 7.4 & $7 \cdot 3,7 \cdot 6$ & 7.4 & $7 \cdot 2,7 \cdot 5$ & 0.06 & 0.06 & $0.00,0.12$ & 0.04 \\
\hline Carbohydrate & $\%$ of energy & 58.9 & $58 \cdot 3,59.5$ & $56 \cdot 1$ & $55 \cdot 5,56 \cdot 6$ & $54 \cdot 7$ & $54 \cdot 2,55 \cdot 3$ & 53.7 & $53 \cdot 1,54 \cdot 2$ & $52 \cdot 0$ & $51 \cdot 4,52 \cdot 6$ & $<0.001$ & -1.63 & $-1.81,-1.44$ & $<0.001$ \\
\hline Alcohol & $\%$ of energy & 0.6 & $0.2,0.9$ & 1.6 & $1 \cdot 2,1.9$ & $2 \cdot 8$ & $2 \cdot 5,3 \cdot 1$ & 3.4 & $3 \cdot 1,3 \cdot 7$ & $4 \cdot 2$ & $3.9,4.5$ & $<0.001$ & 0.84 & $0.73,0.95$ & $<0.001$ \\
\hline Dietary fibre & $\mathrm{g} / 4184 \mathrm{~kJ}$ & 6.5 & $6 \cdot 3,6 \cdot 7$ & 7.4 & $7 \cdot 2,7 \cdot 6$ & 7.7 & $7 \cdot 5,7 \cdot 8$ & 8.3 & $8 \cdot 1,8 \cdot 4$ & 8.8 & $8 \cdot 7,9$ & $<0.001$ & 0.56 & $0.51,0.62$ & $<0.001$ \\
\hline Cholesterol & $\mathrm{mg} / 4184 \mathrm{~kJ}$ & 140 & 134,146 & 162 & 156,167 & 164 & 159,170 & 168 & 162,174 & 186 & 180,192 & $<0.001$ & 9.7 & $7 \cdot 8,11.5$ & $<0.001$ \\
\hline Vitamin A & $\mu \mathrm{g} / 4184 \mathrm{~kJ}$ & 237 & 204,269 & 292 & 261,324 & 315 & 283,346 & 337 & 306,369 & 362 & 330,394 & $<0.001$ & 30.4 & $20 \cdot 1,40.7$ & $<0.001$ \\
\hline Vitamin D & $\mu \mathrm{g} / 4184 \mathrm{~kJ}$ & 3.2 & $2 \cdot 9,3 \cdot 5$ & $4 \cdot 2$ & $3 \cdot 9,4.5$ & $4 \cdot 3$ & $4,4.6$ & 4.8 & $4 \cdot 5,5 \cdot 1$ & 5.4 & $5 \cdot 1,5 \cdot 7$ & $<0.001$ & 0.48 & $0.38,0.58$ & $<0.001$ \\
\hline Vitamin E & $\mathrm{mg} / 4184 \mathrm{~kJ}$ & 3.0 & $2 \cdot 9,3 \cdot 1$ & 3.4 & $3 \cdot 3,3 \cdot 5$ & 3.5 & $3.4,3.6$ & $3 \cdot 7$ & $3 \cdot 6,3 \cdot 7$ & $4 \cdot 0$ & $3 \cdot 9,4 \cdot 1$ & $<0.001$ & 0.26 & $0.23,0.29$ & $<0.001$ \\
\hline Thiamin & $\mathrm{mg} / 4184 \mathrm{~kJ}$ & 0.44 & $0.43,0.45$ & 0.49 & $0.48,0.50$ & 0.52 & $0.50,0.53$ & 0.55 & $0.54,0.56$ & 0.59 & $0.57,0.60$ & $<0.001$ & 0.04 & $0.03,0.04$ & $<0.001$ \\
\hline Riboflavin & $\mathrm{mg} / 4184 \mathrm{~kJ}$ & 0.55 & $0.54,0.57$ & 0.62 & $0.61,0.64$ & 0.65 & $0.64,0.66$ & 0.68 & $0.67,0.70$ & 0.75 & $0.74,0.76$ & $<0.001$ & 0.05 & $0.04,0.05$ & $<0.001$ \\
\hline Vitamin C & $\mathrm{mg} / 4184 \mathrm{~kJ}$ & 47 & 44,49 & 59 & 57,62 & 64 & 62,67 & 76 & 73, 78 & 82 & 80,85 & $<0.001$ & $8 \cdot 2$ & $7.5,9.0$ & $<0.001$ \\
\hline Folate & $\mu \mathrm{g} / 4184 \mathrm{~kJ}$ & 141 & 136,146 & 171 & 166,176 & 182 & 177,187 & 200 & 195, 205 & 228 & 223,233 & $<0.001$ & $21 \cdot 3$ & $19 \cdot 7,22 \cdot 9$ & $<0.001$ \\
\hline $\mathrm{Na}$ & $\mathrm{mg} / 4184 \mathrm{~kJ}$ & 2010 & 1962, 2059 & 2095 & 2048,2143 & 2159 & 2112,2207 & 2227 & 2180,2275 & 2321 & 2273,2369 & $<0.001$ & 82.5 & $67 \cdot 0,98 \cdot 0$ & $<0.001$ \\
\hline $\mathrm{K}$ & $\mathrm{mg} / 4184 \mathrm{~kJ}$ & 1091 & 1069,1113 & 1287 & 1266,1309 & 1373 & 1352,1395 & 1501 & 1479,1522 & 1683 & 1661,1705 & $<0.001$ & 145 & 138,152 & $<0.001$ \\
\hline $\mathrm{Ca}$ & $\mathrm{mg} / 4184 \mathrm{~kJ}$ & 220 & 213,228 & 252 & 245,260 & 272 & 265,279 & 286 & 279,293 & 312 & 305,319 & $<0.001$ & 23.0 & $20 \cdot 6,25 \cdot 3$ & $<0.001$ \\
\hline $\mathrm{Mg}$ & $\mathrm{mg} / 4184 \mathrm{~kJ}$ & 116 & 114,118 & 131 & 129,134 & 138 & 135,140 & 147 & 145,149 & 163 & 161,165 & $<0.001$ & 11.8 & $11 \cdot 1,12.5$ & $<0.001$ \\
\hline $\mathrm{Fe}$ & $\mathrm{mg} / 4184 \mathrm{~kJ}$ & 3.6 & $3.5,3.7$ & $4 \cdot 1$ & $4,4 \cdot 2$ & 4.2 & $4 \cdot 1,4 \cdot 3$ & 4.4 & $4.4,4.5$ & 4.8 & $4.8,4.9$ & $<0.001$ & 0.29 & $0.27,0.32$ & $<0.001$ \\
\hline
\end{tabular}


of fruit, vegetables and key vitamins and minerals, a lower intake of fats and sweets, and lower dietary energy density $^{(14-21)}$. In Japanese adults, we similarly found positive associations of monetary diet cost and intake of pulses, vegetables, fruits, fish, meat, dietary fibre and key vitamins and minerals examined, and lower intake of fats and oils and lower dietary energy density. In contrast, we also found an association with an unfavourable intake pattern, including higher intake of cholesterol and alcohol and lower intake of carbohydrate, which was not seen in previous Western studies. However, the favourable and unfavourable aspects of the relationships between monetary diet cost and diet quality were also observed in previous Japanese studies of young female dietetic students ${ }^{(22)}$ and pregnant women ${ }^{(23)}$. Our study extended these findings by examining other Japanese populations.

The differences in findings between Western and Japanese studies might be at least partly explained by the different food cultures and country-specific dietary intake patterns. For Japanese people, white rice is a main staple food that is consumed at almost every meal. The role of staple food in the Japanese diet is as a main food source of carbohydrate and energy (55-60\% energy), and it connects with main and several side dishes consisting of fish, meat, eggs, vegetables and pulses to provide the macroand micronutrients required ${ }^{(39)}$. In general, grain such as white rice, noodles and bread are relatively inexpensive in comparison with the other foodstuffs included in main and side dishes in Japan (Table 2). According to the results of the $2011 \mathrm{NHNS}^{(40)}$, more than $30 \%$ of Japanese adults, especially almost half of the younger age group (20-49 years), cited higher food prices as the main barrier to choosing and buying fresh foods such as vegetables, fruits, meat and fish. Given that certain socio-economic indicators were significantly associated with monetary diet cost in the present study (Table 1), people of lower socio-economic status with limited food budgets would mainly consume grain such as white rice, noodles and bread, with a relatively low amount and/or less variety of foodstuffs for main and side dishes. This is supported by the results of the latest NHNS examining the relationship between household income and food intake ${ }^{(41)}$. In comparison with people whose household income was more than six million Japanese yen, people whose annual household income was less than two million Japanese yen consumed significantly more grain and less vegetables, fruits and meat.

The unfavourable aspects of diet at the nutrient level were a higher intake of cholesterol, alcohol and sodium and a lower intake of carbohydrate in accordance with increasing diet cost. With the exception of total fat and alcohol, similar results were observed in previous studies $^{(22,23)}$. As mentioned in previous studies ${ }^{(22,23)}$, this might be mainly due to the lower consumption of grain and the food intake patterns associated with lower grain intake with increased diet cost. This is consistent with the 
negative correlation of grain seen with cholesterol (Pearson correlation coefficient, $r=-0 \cdot 19)$ and the positive correlation with carbohydrate $(r=0.57)$ in the present study. In addition, the higher intake of sodium seen with higher dietary cost might be due to a higher intake of vegetables, fish and shellfish, and pulses which are generally accompanied by seasonings with a salty taste, such as salt, soya sauce, miso and salt-containing dressings.

There is now growing awareness that economic concerns strongly influence food choice, particularly in lower socio-economic groups ${ }^{(3,7,42)}$. In the present study, people who had lower energy-adjusted diet cost were likely to have a lower educational attainment, less equivalent household expenditure, large household size, to live in rented houses, and to be younger and physically inactive. Socio-economic status (e.g. income and education) is a well-known factor affecting food choice and eating patterns, because knowledge and awareness of how to eat in a healthy manner could be more common among people in more highly educated groups and with fewer economic constraints $^{(42)}$. Although the association between higher monetary diet cost and a better profile of food and nutrient intake pattern was independent of socio-economic status and lifestyle in the present study (Table 3), it is important to promote healthy food choices and better diet quality among people at risk of lower diet cost by giving nutrition education and by introducing food price policies ${ }^{(43)}$.

Our study has a number of limitations. First, although the study samples were randomly selected from nationally representative households in Japan, only $67.1 \%$ of households sampled took part in the survey ${ }^{(28)}$. Furthermore, the exact response rate at the individual level is not known. If participants with lower socio-economic status were less likely to respond, the relationship between socio-economic status and monetary value of diets might have been underestimated. Second, food prices were estimated from the National Retail Price Survey and websites of a nationally distributed supermarket because of a lack of information on actual food expenditure. In addition, we could not consider foods and beverages purchased and eaten away from home (e.g. at restaurants and other food-service establishments) and varieties of food items (e.g. organic, fresh or frozen, domestic or imported products) because such information was not available in the NHNS. However, we note that a similar methodology has been used in most previous observational studies ${ }^{(14-23)}$. Our estimate of the daily diet cost (1022 Japanese yen/d) was not far from the mean national expenditure for foods at home as calculated by the 2013 Family Income and Expenditure Survey (957 Japanese yen/person per $\mathrm{d})^{(44)}$. Third, dietary intake was assessed by a $1 \mathrm{~d}$ semi-weighed household dietary record, with a combination of the approximate proportions by which each dish was divided among family members. Although the utility of this household dietary record for estimating dietary intake at the individual level has previously been confirmed among young women, the validity of this method has not been examined among men and the other age groups of women. In addition, the days of dietary assessment were intentionally selected from weekdays on only one month (November), which likely introduces some bias in the estimation of average intake. Furthermore, misreporting of self-reported food intake is a source of measurement error. However, the data used here are the only data for individual diet cost and dietary intake in a nationally representative sample, and the results of the present analyses, based on $1 \mathrm{~d}$ dietary record, are consistent with previous studies using diet history questionnaires $^{(22,23)}$. Fourth, sociodemographic and lifestyle information in the CSLC and dietary data in the NHNS were evaluated at different time points, the former in June and the latter in November. This time gap in assessment might have influenced the results slightly, although some sociodemographic variables (e.g. educational attainment) would not have changed between survey times. Finally, monetary value of the diet may act as a marker for other healthy behaviours and/or highly health-conscious habits of the individual and household that could potentially confound associations with food and nutrient intakes. Although we controlled for a wide range of potential confounders and other influences on food and nutrient intakes, such as socio-economic status and lifestyle variables, we cannot rule out unmeasured or residual confounding in an observational study.

\section{Conclusion}

In conclusion, the present cross-sectional study of a representative sample of Japanese adults showed that higher monetary value of diets was associated with a higher intake of favourable food groups and nutrients, whereas lower monetary value of diets was associated with a higher intake of carbohydrate with less key vitamins and minerals. Given that certain socio-economic subgroups in Japan consume diets of lower monetary value that result in a lower quality of food and nutrient intake pattern, further cross-sectional and prospective studies using representative data to examine the effects of monetary value of diets on long-term health outcomes are required.

\section{Acknowledgements}

Financial support: This work was supported in part by a Grant-in-Aid for Young Scientists (B) from the Japan Society for the Promotion of Science. The funders had no role in the design, analysis or writing of this article. Conflict of interest: None of the authors have any personal or financial conflicts of interest to declare. Authorship: H.O. created the monetary diet cost database for estimation from the diet records, conducted the statistical 
analysis, interpreted the data and wrote the manuscript. K.M. assisted in diet cost database establishment, data interpretation and manuscript preparation. S.S. assisted in manuscript preparation. All authors contributed to and approved the final manuscript. Ethics of human subject participation: This survey was conducted according to the guidelines of the Declaration of Helsinki and verbal informed consent was obtained from all individual subjects. The Comprehensive Survey of Living Conditions and the National Health and Nutrition Survey, conducted by the Ministry of Health, Labour and Welfare, Japan, have stringent protocols and procedures that ensure confidentiality and protect individual participants from being identified. Additionally, the present secondary analysis was based on a public-use data set consisting solely of information that had already been anonymized. Thus, Institutional Review Board approval was not required.

\section{References}

1. Lennernas M, Fjellstrom C, Becker W et al. (1997) Influences on food choice perceived to be important by nationallyrepresentative samples of adults in the European Union. Eur J Clin Nutr 51, Suppl. 2, S8-S15.

2. Glanz K, Basil M, Maibach E et al. (1998) Why Americans eat what they do: taste, nutrition, cost, convenience, and weight control concerns as influences on food consumption. J Am Diet Assoc 98, 1118-1126.

3. Drewnowski A \& Darmon N (2005) Food choices and diet costs: an economic analysis. J Nutr 135, 900-904.

4. Drewnowski A, Darmon N \& Briend A (2004) Replacing fats and sweets with vegetables and fruits - a question of cost. Am J Public Health 94, 1555-1559.

5. Andrieu E, Darmon N \& Drewnowski A (2006) Low-cost diets: more energy, fewer nutrients. Eur J Clin Nutr 60 , 434-436.

6. Maillot M, Darmon N, Darmon M et al. (2007) Nutrientdense food groups have high energy costs: an econometric approach to nutrient profiling. J Nutr 137, 1815-1820.

7. Darmon N \& Drewnowski A (2015) Contribution of food prices and diet cost to socioeconomic disparities in diet quality and health: a systematic review and analysis. Nutr Rev 73, 643-660.

8. Beydoun MA \& Wang Y (2008) How do socio-economic status, perceived economic barriers and nutritional benefits affect quality of dietary intake among US adults? Eur J Clin Nutr 62, 303-313.

9. Drewnowski A \& Darmon N (2005) The economics of obesity: dietary energy density and energy cost. Am J Clin Nutr 82, 1 Suppl., 265S-273S.

10. Ricciuto LE \& Tarasuk VS (2007) An examination of incomerelated disparities in the nutritional quality of food selections among Canadian households from 1986-2001. Soc Sci Med 64, 186-198.

11. Darmon N \& Drewnowski A (2008) Does social class predict diet quality? Am J Clin Nutr 87, 1107-1117.

12. James WP, Nelson M, Ralph A et al. (1997) Socioeconomic determinants of health. The contribution of nutrition to inequalities in health. BMJ 314, 1545-1549.

13. Lahelma E, Martikainen P, Laaksonen M et al. (2004) Pathways between socioeconomic determinants of health. J Epidemiol Community Health 58, 327-332.
14. Cade J, Upmeier H, Calvert C et al. (1999) Costs of a healthy diet: analysis from the UK Women's Cohort Study. Public Health Nutr 2, 505-512.

15. Darmon N, Briend A \& Drewnowski A (2004) Energy-dense diets are associated with lower diet costs: a community study of French adults. Public Health Nutr 7, 21-27.

16. Schroder H, Marrugat J \& Covas MI (2006) High monetary costs of dietary patterns associated with lower body mass index: a population-based study. Int J Obes (Lond) 30, $1574-1579$.

17. Maillot M, Darmon N, Vieux F et al. (2007) Low energy density and high nutritional quality are each associated with higher diet costs in French adults. Am J Clin Nutr 86, 690-696.

18. Waterlander WE, de Haas WE, van Amstel I et al. (2010) Energy density, energy costs and income - how are they related? Public Health Nutr 13, 1599-1608.

19. Rehm CD, Monsivais P \& Drewnowski A (2011) The quality and monetary value of diets consumed by adults in the United States. Am J Clin Nutr 94, 1333-1339.

20. Morris MA, Hulme C, Clarke GP et al. (2014) What is the cost of a healthy diet? Using diet data from the UK Women's Cohort Study. J Epidemiol Community Health 68, 1043-1049.

21. Rehm CD, Monsivais P \& Drewnowski A (2015) Relation between diet cost and Healthy Eating Index 2010 scores among adults in the United States 2007-2010. Prev Med 73, $70-75$.

22. Murakami K, Sasaki S, Okubo H et al. (2007) Monetary costs of dietary energy reported by young Japanese women: association with food and nutrient intake and body mass index. Public Health Nutr 10, 1430-1439.

23. Murakami K, Miyake Y, Sasaki S et al. (2009) Monetary diet cost is associated with not only favorable but also unfavorable aspects of diet in pregnant Japanese women: the Osaka Maternal and Child Health Study. Environ Health Insights 3, 27-35.

24. Murakami K, Miyake Y, Sasaki S et al. (2009) Education, but not occupation or household income, is positively related to favorable dietary intake patterns in pregnant Japanese women: the Osaka Maternal and Child Health Study. Nutr Res 29, 164-172.

25. Fukuda Y \& Hiyoshi A (2012) High quality nutrient intake is associated with higher household expenditures by Japanese adults. Biosci Trends 6, 176-182.

26. Okubo H, Sasaki S, Murakami K et al. (2015) Designing optimal food intake patterns to achieve nutritional goals for Japanese adults through the use of linear programming optimization models. Nutr J 14, 57.

27. Ministry of Health, Labour and Welfare, Japan (2014) Comprehensive Survey of Living Conditions, 2013 (in Japanese). http://www.mhlw.go.jp/toukei/saikin/hw/k-tyosa/ k-tyosa13/dl/16.pdf (accessed November 2015).

28. Ministry of Health, Labour and Welfare, Japan (2015) The National Health and Nutrition Survey, 2013 (in Japanese). http://www.mhlw.go.jp/bunya/kenkou/eiyou/ dl/h25-houkoku.pdf (accessed November 2015).

29. Ikeda N, Takimoto H, Imai S et al. (2015) Data resource profile: the Japan National Health and Nutrition Survey (NHNS). Int J Epidemiol 44, 1842-1849.

30. Statistics Bureau, Ministry of Internal Affairs and Communications (2011) Population and Households of Japan 2010: Outline of the 2010 population census of Japan (in Japanese). http://www.stat.go.jp/english/data/kokusei/2010/ pdf/outline.pdf (accessed November 2015).

31. Iwaoka F, Yoshiike N, Date C et al. (2001) A validation study on a method to estimate nutrient intake by family members through a household-based food-weighing survey. J Nutr Sci Vitaminol (Tokyo) 47, 222-227. 
32. Science and Technology Agency (2005) Standard Tables of Food Composition in Japan, Fifth Revised and Enlarged Edition. Tokyo: Printing Bureau of the Ministry of Finance (in Japanese).

33. Ledikwe JH, Blanck HM, Khan LK et al. (2005) Dietary energy density determined by eight calculation methods in a nationally representative United States population. $J$ Nutr 135, 273-278.

34. Hebestreit A, Börnhorst C, Pala V et al. (2014) Dietary energy density in young children across Europe. Int J Obes (Lond) 38, Suppl. 2, S124-S134.

35. Price Statistics Office, Statistics Bureau (2014) Retail Price Survey, 2013 (in Japanese). http://www.stat.go.jp/data/ kouri/index.htm (accessed November 2015).

36. Organisation for Economic Co-operation and Development (2008) Growing Unequal? Income Distribution and Poverty in OECD Country. Paris: OECD.

37. World Health Organization (2000) Obesity: Preventing and Managing the Global Epidemic. Report of a WHO Consultation. WHO Technical Report Series no. 894. Geneva: WHO.

38. Willett WC, Howe GR \& Kushi LH (1997) Adjustment for total energy intake in epidemiologic studies. Am J Clin Nutr 65, 4 Suppl., 1220S-1228S.

39. Adachi M (1984) A study on the core-dishes and these combination as a framework of nutrition education on the basis of dish-selecting method. J Health Hum Ecol 50, 70-107.

40. Ministry of Health, Labour and Welfare, Japan (2013) The National Health and Nutrition Survey, 2011 (in Japanese). http://www.mhlw.go.jp/bunya/kenkou/eiyou/ dl/h23-houkoku.pdf (accessed November 2015).

41. Ministry of Health, Labour and Welfare, Japan (2015) The National Health and Nutrition Survey, 2014 (in Japanese). http://www.mhlw.go.jp/file/04-Houdouhappyou-10904750Kenkoukyoku-Gantaisakukenkouzoushinka/0000106547.pdf (accessed December 2015).

42. Timmins KA, Hulme C \& Cade JE (2015) The monetary value of diets consumed by British adults: an exploration into sociodemographic differences in individual-level diet costs. Public Health Nutr 18, 151-159.

43. Waterlander WE, de Boer MR, Schuit AJ et al. (2013) Price discounts significantly enhance fruit and vegetable purchases when combined with nutrition education: a randomized controlled supermarket trial. Am J Clin Nutr 97, 886-895.

44. Statistics Bureau, Ministry of Internal Affairs and Communications (2014) Family Income and Expenditure Survey, 2013 (in Japanese). http://www.e-stat.go.jp/SG1/estat/List. do?lid=000001117250. (accessed November 2015). 